\title{
Conditioned aversion to morphine with naloxone
}

\author{
JOSEPH W. TERNES \\ Caribbean Primate Research Center, University of Puerto Rico \\ Sabana Seca, Puerto Rico 00794
}

\begin{abstract}
Four groups of male Wistar rats were trained to self-administer morphine by drinking morphinized solution. Following an 8-day, two-bottle test during which the subjects demonstrated that they had acquired a preference for morphine over water, morphine injection was substituted for morphine solution for 7 days. Morphine solution was then paired with injection of naloxone in the experimental group and physiological saline in the control group. Subsequently a two-bottle preference test between morphine solution and water was given for 6 days. Maintenance during this extinction period involved either daily injection of morphine in experimental and control subgroups or daily injection of physiological saline in the second experimental and control subgroups. Results indicated that a profound aversion to morphine was conditioned in the experimental group regardless of whether the urgency to drink morphine to relieve withdrawal stress was controlled. The data are discussed as an example of prepared learning.
\end{abstract}

Revuski and Garcia (1970) found that hungry rats would not associate postingestional repletion of glucose with the consumption of nonnutritive solutions. But Parker, Failor, and Weidman (1973) demonstrated that beneficial postingestional consequences can be associated with a novel flavor when morphine withdrawal was the relevant need state. They suggested that readiness to associate beneficial consequences with consummatory cues may depend on the type of need that is satisfied. Ternes (in press, A) found that rats forced to drink weak solutions of morphine for 84 days acquired a preference for morphone solution over water when both were made available in a two-bottle test. However, the length of the induction period (12 weeks) indicated that rats are relatively unprepared to learn to associate bitter morphine taste with the beneficial postingestional consequence of relief from withdrawal stress. Thus, rather than the type of need satisfied, the type of stimulus tested appears to be the more relevant factor affecting readiness to associate a consequence with a consummatory cue.

Weisinger, Parker, and Skorupski (1974) have shown that insulin and formalin injections were both effective in producing conditioned taste aversions except when they followed the consumption of sucrose or sodium, respectively. These findings suggest the existence of biological constraints which apply to conditioned aversions as well as to preferences. Fernandez and Ternes (in press) have conditioned aversions to morphine in dependent raț - by associating its taste with postingestional lithium illness. The subjects in this study needed to ingest morphine in order to avoid withdrawal stress. Thus, they were very familiar with the taste of the test substance. The authors suggested that the demonstration of an aversion under circumstances which would ordinarily preclude conditioning was evidence that rats are highly prepared to associate the bitter taste of morphine with illness.
Recently Ternes (in press, B) found that naloxone, an antagonist of morphine will produce aversions to sucrose in morphine dependent rats but not in nondependent controls. The purpose of the present experiment was to use naloxone to condition aversions to morphine in dependent rats which were accustomed to self-administer their daily drug dose by drinking weak morphinized solutions.

\section{METHOD}

\section{Subjects}

Subjects were 32 180-day-old male Wistar rats which had previously learned to drink morphinized solution in order to avoid withdrawal stress. They were housed in standard Hoeltge wire rat cages in an open air animal shelter at the Caribbean Primate Research Center, Sabana Seca, Puerto Rico.

\section{Procedure}

Preconditioning. The dependency induction and preference test has been described elsewhere (Ternes in press, A). Basically it involved providing rats with a solution of $.3 \mathrm{mg} / \mathrm{ml}$ morphine sulphate in tap water as the only source of liquid for 84 days. Preference for morphine solution over water in an 8-day two-bottle preference test was interpreted as evidence that morphine dependence had been acquired.

Conditioning. Following the 8-day two-bottle preference test, subjects were randomly assigned to four groups of eight rats each. All subjects were subsequently provided with tap water as their sole source of liquid for 7 days. During this period their mean daily dose of morphine, as calculated from their morphine consumption during the 8 -day preference test, was administered each morning in the form of an intramuscular injection. On the eighth day of the experiment, all subjects were deprived of food and water. The following day at noon, a $.3-\mathrm{mg} / \mathrm{ml}$ morphinized solution was provided for $20 \mathrm{~min}$. All subjects were observed to drink morphine solution during this period. Immediately following the presentation of the morphine solution, 16 subjects were injected intramuscularly (IM) with 4-mg naloxone hydrochloride in a 1 -cc vehicle of sodium chloride while the remaining 16 subjects were injected with 1 -cc physiological saline.

Twenty-four hours after conditioning, a two-bottle extinction test between . $3-\mathrm{mg} / \mathrm{ml}$ morphine solution and water was 


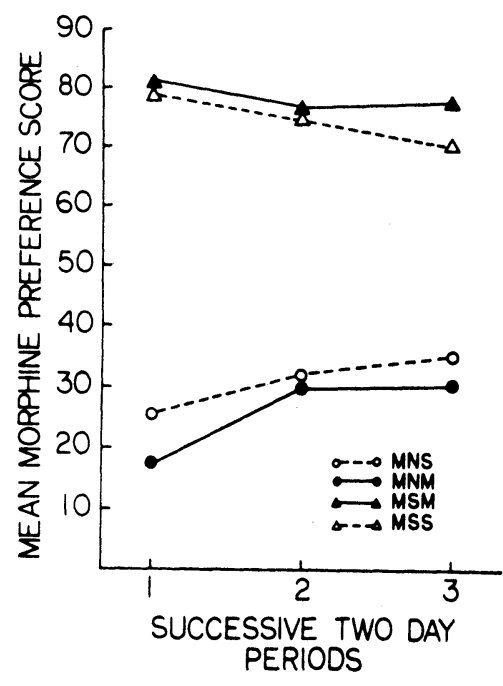

Figure 1. Group mean morphine scores during the 6-day extinction test (Group MNS: pretreatment was morphine, treatment was naloxone, posttreatment maintenance was saline; Group MNM: morphine, naloxone, morphine; Group MSM: morphine, saline, morphine; Group MSS: morphine, saline, saline).

initiated. Preference testing was continued for 6 consecutive days. The four groups were distinguished on the basic two factors: the type of treatment and the type of posttreatment maintenance. Treatments consisted of naloxone or saline IM injection paired with morphine taste on the treatment day. Maintenance consisted of daily IM injections of the subjects' mean daily morphine dose in morphine maintenance groups or of equivalent amounts of physiological saline in saline maintenance groups. The four groups were identified as follows: morphine, naloxone, morphine (MNM); morphine, naloxone, saline (MNS); morphine, saline, morphine (MSM); morphine, saline, saline (MSS). Morphine consumption for each subject was recorded as the percentage of daily liquid consumption (morphine + water) that was morphine.

\section{RESULTS}

\section{Preconditioning}

The data obtained during the 8-day two-bottle preference test was analyzed by means of a 4 by 8 analysis of variance (ANOVA) with repeated measures on the second factor (Winer, 1962). The groups effect, the days effect, and the Groups by Days interaction were not significant. It was concluded that there were no significant differences between the groups prior to conditioning.

\section{Postconditioning}

A 2 by 2 by 6 ANOVA with repeated measures on the last factor was performend on the postconditioning extinction test data. Due to the death of a subject in the MSS group, an unweighted means analysis was used (Winer, 1962). The groups effect $(\mathrm{F}=59.25, \mathrm{df}=3 / 29$, $\mathrm{p}<.001)$ was highly significant. The main effects of days $(\mathrm{F}=1.056, \mathrm{df}=5 / 145, \mathrm{p}>.5)$ and of maintenance $(\mathrm{F}=.534, \mathrm{df}=2 / 27, \mathrm{p}>.5)$ were not significant.
However, the Groups by Days interaction was significant $(F=2.398, \mathrm{df}=5 / 145, \mathrm{p}<.05)$. None of the other interactions were significant. Figure 1 shows the group mean morphine preference scores as a function of consecutive two day extinction periods.

\section{DISCUSSION}

The present experiment was performed in an attempt to extend the results of Fernandez and Ternes (in press). They suggested that learning to avoid bitter morphine taste was an example of prepared learning. Their results, which were equivocal in this respect, were explained by positing interference from the effects of familiarity with the test substance, morphine solution, and the effects of increasing urgencies to drink morphine as the interval since the last dose increased. Familiarity with the test substance was controlled in the present experiment by substituting morphine injection for the usual morphine solution during the week prior to conditioning. Likewise, the urgency to drink morphine in order to relieve withdrawal stress during the extinction test was controlled by maintaining subgroups of both the experimental and control groups on daily morphine injections. The results of the ANOVA indicate an aversion to morphine which did not extinguish during the 6 days of the extinction test in the experimental groups. The significant Groups by Days interaction suggests that some recovery did occur, however. The fact that the maintenance effect was not significant indicates that morphine injections did not potentiate the aversion (depress morphine drinking) nor did it inhibit it (elevate morphine drinking) within the period of this study. The aversion demonstrated in the MNS group suggests that even the most severe abstinence symptoms, which can be expected to occur between 48 and $96 \mathrm{~h}$ after conditioning, were not sufficient to override the association between naloxone induced withdrawal stress and morphine taste.

The present study demonstrates that an aversion for bitter morphine taste was easily learned. However, Ternes (in press, A) found that rats can learn a preference for bitter morphine taste only with extended training. Handal (1965) and Wolf (1969) have shown that sodium deficient rats preferentially consume sodium. Smith and Duffy (1957) have demonstrated similar findings for sucrose with rats. Weisinger, Parker, and Skorupski (1974) reported that insulin and formalin would not produce aversions to sucrose and sodium respectively. They did not preclude the possibility that further training would produce the desired aversions; however, they suggest that it would be a case of unprepared or perhaps contraprepared learning. These results suggest an empirical generalization: Organisms prepared to learn a preference for a gustatory stimulus are unprepared to learn to avoid such a stimulus whereas, organisms prepared to learn to avoid a gustatory stimulus are unprepared to learn to prefer that stimulus. Thus, preferences or aversions relatively easy to acquire are relatively difficult to modify, whereas preferences and aversions relatively difficult to acquire are relatively easy to modify.

\section{REFERENCES}

Fernandez, B., \& Ternes, J. W. Conditioned aversion to morphine with lithium chloride in morphine dependent rats. Bulletin of the Psychonomic Society, 1975, in press.

Handal, P. J. Immediate acceptance of sodium salts by sodium deficient rats. Psychonomic Science, 1965, 3, 315-316.

Parker, L., Failor, A., \& Weidman, K. Conditioned preferences in the rat with an unnatural need state: Morphine withdrawal. Journal of Comparative and Physiological Psychology, 1973, 82, 294-300.

Revuski, S. H., \& Garcia, J. Learned associations over long delays. In G. H. Bower and J. T. Spence (Eds.), The psychology of learning and motivation: Advances in research and theory. New York: Academic Press, 1970. 
Smith, M. H., \& Duffy, M. Consumption of sucrose and saccharin by hungry and satiated rats. Journal of Comparative and Physiological Psychology, 1957, 50, 65-69.

Ternes, $J$. W. induced preference for morphine in rats. Bulletin of the Psychonomic Society, 1975a, in press.

Ternes, J. W. Naloxone induced aversion to sucrose in morphine dependent rats. Bulletin of the Psychonomic Society, 1975b, in press.

Weisinger, R. S., Parker, L. F., \& Skorupski, J. D. Conditioned taste aversions and specific needs states in the rat. Journal of
Comparative and Physiological Psychology, 1974, 87, 655-660.

Winer, B. J. Statistical principles in experimental design. New York: McGraw-Hill, 1962.

Wolf, G. Innate mechanisms for regulation of sodium intake. In C. Pfaffmann (Ed.), Olfaction and taste. New York: Rockefeller University Press, 1969.

Bulletin of the Psychonomic Society

1975, Vol. 5 (4), 294-296

\title{
Alley section effects of magnitude of partial reward after extensive acquisition training
}

\author{
E. J. CAPALDI and MICHAEL R. FREESE \\ Purdue University, West Lafayette, Indiana 47907
}

\begin{abstract}
Rats were given either a small or a large magnitude of partial reward (100 trials) in a runway and 50 extinction trials. The initial trial acquisition superiority associated with the larger magnitude of partial reward maintained itself throughout acquisitions in the start section of the runway but disappeared by the last block of 25 trials in the run section and following the first block of 25 trials in the goal section. In extinction there was a marginal tendency, totally absent in the start and goal sections, for resistance to extinction to increase as magnitude of partial reward increased. These results suggest that the early trial acquisition and extinction superiority associated with larger magnitudes of partial reward are reduced by late trial inhibitory effects which increase toward the goal section and as magnitude of partial reward increases.
\end{abstract}

The effects of magnitude of partial reward on acquisition and extinction appear to depend upon level of acquisition training (see Capaldi \& Freese, 1974). That is, both the acquisition and extinction superiority associated with larger magnitudes of partial reward earlier in acquisition training tend to disappear following more extensive training (McCain, 1970), and, indeed, following extensive acquisition training, resistance to extinction may actually decrease as magnitude of partial reward increases (Campbell, Crumbaugh, Rhodus, \& Knouse, 1971; Capldi \& Freese, 1974).

There is reason to suppose (see Capaldi \& Levy, 1972) that the effects of magnitude of partial reward on acquisition and extinction following extensive acquisition training may depend upon section of the runway but data on this point are not available. McCain (1970) did not report alley section findings and the section findings of Campbell et al. (1971), while suggestive, may be peculiar to the alternating schedule of reward and nonreward employed in that investigation. This investigation employed a large vs. a small magnitude of partial reward on an irregular training schedule for 100 acquisition trials, followed by 50 extinction trials with performance being measured over the early (start),

This research was supported in part by National Institute of Child Health Development Grant 5R HD 04379-03 to the first author and by a Purdue University David Ross predoctoral Fellowship to the second author.

Requests for reprints should be sent to E. J. Capaldi, Department of Psychological Sciences, Purdue University, West Lafay ette, Indiana 47907. middle (run) and late (goal) portions of the alley.

\section{METHOD}

\section{Subjects}

The subjects were 20 male albino rats, 100 days old at the beginning of the experiment, purchased from the Holtzman Co., Madison, Wisconsin. The mean weights of the animals were monitored and the two groups did not differ in weight either at the beginning of acquisition $[F(1,18)=1.88, p>.20]$ or on the first day of extinction $(F<1)$.

\section{Apparatus}

The gray runway was $208.4 \mathrm{~cm}$ long, $10.2 \mathrm{~cm}$ wide, with $22.9 \mathrm{~cm}$ high sides. It was covered with $1.3-\mathrm{cm}$ hardware cloth. A $20.3-\mathrm{cm}$ long floor treadle suspended over the microswitch constituted the initial portion of the alley. When the treadle was depressed by the rat, whose front paws were always placed at the extreme forward edge, the first clock $(.01 \mathrm{sec})$ was started. Interrupting a photobeam $5.1 \mathrm{~cm}$ beyond the treadle stopped Clock 1 (start time) and started Clock 2. Interrupting a photobeam $131.1 \mathrm{~cm}$ beyond the first photobeam stopped Clock 2 (running time) and started Clock 3. Interrupting a photobeam $30.4 \mathrm{~cm}$ beyond the second photobeam and $6.4 \mathrm{~cm}$ in front of the brass $5.1 \times 10.2 \times 3.8 \mathrm{~cm}$ foodcup stopped Clock 3 (goal time). The brass cup contained a metal inset, $3.8 \times 3.2 \times 1.9 \mathrm{~cm}$, which contained the reward pellets on goalbox placements in pretraining and on all reward trials during acquisition training. A guillotine-type brass door prevented retracing back into the runway once the rat interrupted the third photobeam in the goal section of the alley.

\section{Procedure \\ Upon arrival at the laboratory, subjects were housed in individual cages where the food and water was supplied on an} ad-lib basis for 5 days. Deprivation, which consisted of $13 \mathrm{~g} /$ day 